Journal Wetenskap Health

\title{
Reproductive Health Education on Attitudes about Teenage Girls Premarital Sex
}

\author{
Johnstune Nehioshon $^{1}$, Buniface Mechirie ${ }^{1}$, Mkamzie Ndambuki ${ }^{1}$ \\ ${ }^{1}$ Faculty of Health Sciences, University of Nairobi, Kenya
}

\begin{abstract}
Sexual health is described as a condition of total physical, mental, and social well-being in all aspects of sexuality, not only the absence of sickness or impairment. Reproductive rights, on the other hand, are the rights to reach the highest levels of sexual and reproductive health. This includes the freedom to make reproductive choices without fear of discrimination or violence. Complete knowledge, as well as the instillation of religious beliefs and standards, may help to protect children and adolescents from sexual offenses.
\end{abstract}

Keywords: Reproductive Health, Premarital Sex, Adolescent Girls

\section{Introduction}

Teenagers are the next generation, the nation's buds and the determinants of the future which are the basic capital for the development of the nation. Therefore, the existence of youth groups cannot be ignored. The World Health Organization (WHO) noted that about one-fifth of the world's population consists of adolescents and 900 million of them are in developing countries. The size of the adolescent population will affect the development of social, economic and demographic aspects both now and in the future. According to the Demographic and Youth Health Survey (IDHS-R) in 2007, the adolescent population needs serious attention because teenagers are of school age and working age, they are very at risk of reproductive health problems, namely premarital sexual behavior.

As a result of the lack of information on reproductive health, one of which is that adolescents have had sex actively without sufficient knowledge. Lack of understanding of sexual behavior in adolescents is very detrimental to adolescents themselves including their families, because at this time adolescents experience important developments, namely cognitive, emotional, social, and sexual. This development starts from the age of 12 to 20 years.

This lack of understanding is caused by various factors including: customs, culture, religion, and lack of understanding from the right sources (Locke \& Bailey, 2013; Tamanaha, 2008). This lack of understanding is actually very detrimental to youth groups and their families. Based on the results of the study, regarding adolescent sexual behavior with a sample of 1250 people, one of the efforts to increase students' knowledge about premarital sex properly and correctly is to provide health education/health promotion. Health promotion is considered important because the information provided contains knowledge and messages to students so as not to get caught in the wrong association. Lack of knowledge and attitudes can lead to cases such as pregnancy out of wedlock. There is an effect of adolescent health counseling (AHC) on adolescent sexual knowledge and attitudes. Based on this background,

Article Info:

Received: April 12, 2021

Revised: May 18, 2021

Accepted: May 27, 2021 
the researchers are interested in conducting research on the effect of health promotion on reproductive health on adolescent knowledge and attitudes about premarital sex.

Table 1. Student Distribution by Class

\begin{tabular}{|l|c|c|c|}
\hline \multirow{2}{*}{ Class } & \multicolumn{2}{c|}{ Sum } & \multirow{2}{*}{ Sum } \\
\cline { 2 - 3 } & Man & Woman & \\
\hline X-1 & 9 & 9 & 18 \\
\hline X-2 & 17 & 5 & 22 \\
\hline XI ES 1 & 10 & 7 & 17 \\
\hline XI ES 2 & 10 & 7 & 17 \\
\hline XI-SS & 12 & 3 & 14 \\
\hline XII-ES 1 & 4 & 10 & 16 \\
\hline XII-ES 2 & 4 & 12 & 13 \\
\hline XII-SS 1 & 10 & 3 & 15 \\
\hline XII-SS 2 & 10 & 5 & 147 \\
\hline Sum & 86 & 61 & \\
\hline
\end{tabular}

Reproductive Health in Adolescents During the International Conference on Population and Development (ICPD) in 1994, the International Society repeatedly upheld adolescents' rights to accurate information on adolescent reproductive health (ARH) and reproductive health $(\mathrm{RH})$ services, including counseling. The worldwide community has also reminded parents of their rights and obligations, which include ensuring that their teens have access to the services and information they need on reproductive health (Marques \& Ressa, 2013; Adongo et al., 2013). 1 Adolescents should be aware of reproductive health since it is critical for them to do so in order to better prepare for family life. As a result, it is believed that teenagers would be able to better control their reproductive functions and processes, as well as establish appropriate sexual conduct. Teenagers' awareness of reproductive health serves as a guidance for them to act in a healthy and responsible way, but not all adolescents get adequate and accurate reproductive health knowledge. Adolescents may engage in dangerous conduct as a result of their lack of information and awareness.

Table 2. Distribution of Respondents by Age

\begin{tabular}{|l|l|l|}
\hline Age & Frequency $(\mathrm{F})$ & Percentage $(\%)$ \\
\hline 15 Years Old & 2 & 3,3 \\
\hline 16 Years Old & 11 & 18,3 \\
\hline 17 Years Old & 44 & 73,3 \\
\hline 18 Years Old & 3 & 5,0 \\
\hline Total & 60 & 100 \\
\hline
\end{tabular}

In this scenario, professionals in this area recognize the need for knowledge, direction, and support from the surrounding environment so that healthy growth and development may occur in the system of change, resulting in future teens becoming physically, spiritually, and socially healthy adults. The government has made AHC a nationwide program since 2000. The AHC program is a service that provides information, counseling, and life skills education to assist teenagers maintain excellent reproductive health. Adolescent reproductive health (AHC) is described as a healthy state of reproductive systems, functions, and processes in adolescents, i.e. men and women aged 10 to 24 years. 2 Adolescence is crucial for reproductive health for three reasons. are the following: 1 . Adolescence (ages 10 to 19 years) is a unique and significant time since it is a phase of 
human reproductive organ growth, often known as puberty. Adolescence is marked by fast bodily (organobiological) and psychological (mental-emotional) changes that are not balanced. This significant shift might be perplexing for teens who are experiencing it, as it necessitates knowledge, direction, and support from their surroundings in order for them to grow and develop into healthy adults, both physically, cognitively, and psychosocially. 3 . Adolescent males and females are often treated differently in specific social contexts. Adolescence is a period of developing independence for males, but it is also a period when all sorts of constraints emerge for young women (in the past, girls began to be secluded when they started menstruating). The reproductive system will be disrupted as a result of adolescent health (Golub, 2000; Warren \& Perlroth, 2001; Zhu et al., 2021; Townsend et al., 2020). Some conditions that harm adolescent health, especially adolescent reproductive health, are listed below.

\section{Premarital Sex in Teenagers}

It's not so much that sexual knowledge has anything to do with the genitals; it's something that relates to personal interactions between men and women. A kiss is done to increase sexual stimulation, such as when it is done on the lips followed with sexual stimulation of sensitive areas that may increase sexual arousal. Closed-lipped kissing is an extremely prevalent kissing practice. Lying over one's shoulder is one way to kiss around the neck down. Necking is a phrase that refers to an affectionate kiss around the neck and a more intense embrace.

Table 3. Premarital Sex Knowledge

\begin{tabular}{|l|l|l|}
\hline Knowledge & Frequency (N) & Percentage (\%) \\
\hline Good & 26 & 43,3 \\
\hline Less & 34 & 56,7 \\
\hline Total & 60 & 100 \\
\hline
\end{tabular}

It is unnecessary to massage delicate regions of the body, such as the breasts and genital organs. This is a deeper step than necking, not a first step. It includes a sensation of caressing and stroking a partner's body, including rubbing up and down the arms, over the chest, and on the breasts, thighs, and/or genital region, either within or outside of clothes. When two individuals engage in sexual intercourse, whether male-to-female or female-tomale, the resulting union is sexual, and results in an erect penis entering the vagina for pleasure.

\section{Problems that Occur in Adolescent Sex}

Increased sexual drive, libido, and increased teenage sexuality are hormonal changes with this boost in sexual desire, certain sorts of sexual conduct will be needed to handle it. The age of marriage can't be brought forward for two reasons. The first is because the law requires that the age of marriage be established, which in this case is a delay caused by the passage of time. The second is because current social norms are more and more stringent on the importance of marriage (education, employment, mental preparation, and others).

Religious rules still apply whenever a person is barred from having sex before marriage even if they're not allowed to be married until a later age. Prohibition not only extends to other activities such as kissing and masturbating, but it also includes other illegal actions such as using illicit drugs. There is a greater propensity for teens to break these rules if they are unable to control themselves. As the number of violations increase, so does the likelihood of more violations owing to the rise of information and sexual stimulation, owing 
to the transmission of this information and stimulation by the mass media, aided by modern technology (video cassette, VCD, mobile phone, internet, etc.).

It's not the parents' fault that the information isn't passed on to the children, either because they're ignorant or because they've created a culture of silence around the subject. Society as a whole has seen a rise in the inclination for women and men to associate freely in society because of the advancement of women's roles and education, such that women's place in society is now equal to males.

\section{Factors that Influence Premarital Sexual Behavior}

The forces that exist inside the organization (knowledge, aspects of reproductive health, attitudes towards sexual and reproductive health services, behavior, perceived vulnerability to risk, reproductive health, lifestyle, self-control, social activities, selfconfidence, age, religion, and marital status). External influences such as being in touch with sources of information, familial, social, cultural, and values and conventions as social support for specific actions.

Table 4. Premarital Sex Attitudes

\begin{tabular}{|l|l|l|}
\hline Attitude & Frequency (N) & Percentage (\%) \\
\hline Good & 48 & 80,0 \\
\hline Less & 12 & 20,0 \\
\hline Total & 60 & 100 \\
\hline
\end{tabular}

Some kids believe that their parents refuse to discuss about sex before marriage, so they then turn for alternate sources of knowledge, such as friends or the media. A number of studies have shown that teenagers are in desperate need of education on sexual and reproductive concerns. Adolescents are particularly vulnerable to getting erroneous information about sex from their peers, not from health professionals, school, or parents. Environmental variables that have a large role in teenage reproductive behavior include such things as familial considerations. A large percentage of youths who have sex before marriage come from divorced or divorced households, homes with many interpersonal problems and disputes.

An ideal emotional existence for the child's personality development can only be achieved in the context of harmonious parental interactions. Youngsters that often battle with their parents have a difficult time communicating in the family, and as a result, some children just "evade" their family. Children who live in an incomplete family, such as owing to divorce, death, or families with less economic advantages, may be hindered in their mental development.

To find out about how different variables impact sexual activity in teenagers prior to their engagement in relationships, we analyzed information relating to each of these three areas: parents and adolescents, peer pressure, and religion. Several additional elements that affect teenage sexual activity include hormonal changes, the age at which people marry, the frequency with which the population receives information via the media, taboos, conventions in society, and the growing open connection between men and women.

\section{The Impact of Premarital Sex Behavior}

In the eyes of the law, unmarried teenagers who engage in sexual activity risk becoming pregnant or spreading sexually transmitted illnesses. Because we know that there are many harmful repercussions of premarital sex, we should be very cautious and not engage 
in sexual activities until we are both ready. This will help ensure our health and that of our potential children. Hundreds of kids have fallen into premarital sex, with no less than tens of thousands of them affected. Young people who have sexual relations before marriage tend to be less financially capable. Outside influences such as media may contribute to the decision to have premarital sex since one may choose to hang out in an atmosphere where premarital sex is more prominent. Here are some of the biggest risks of having sex before marriage.

If it can be established that a person had premarital sex, then he or she carries that weight of guilt throughout their life. In addition to the perpetrator's family, the extended family of the offender also experienced shame, making it a heavy burden for all of them. Occasional sexual activity should not result in pregnancy unless it occurs within the fertile period. If you engage in premarital sex, you will put a significant mental strain on yourself and your partner. This pregnancy, which is termed a "accident," creates significant hardship and even tragedy for the people who had it, as well as the perpetrators and their children. The act of abortion is illegal and against the law. It is believed that abortion might cause infertility and perhaps uterine cancer. The risk of abortion resulting in death is significant, since it may happen in the process of a failed abortion.

A sexually transmitted illness will be passed via both intimate partners and even their kids. The spread is from having sex before to marriage with several partners. A single sexual encounter with someone who is afflicted with one of the venereal diseases may spread the illness to both the receiver and the contacts. One of the viruses that may be transferred during sexual activity is the HIV virus. Pregnancy happens when a sperm fertilizes an egg, with the fertilization process starting on the female side and proceeding to the male side. When it comes to having sex, things often start off with a bang. The pregnancy process in teenagers frequently comes about due to the lack of understanding on the part of teenagers of what's going on.

\section{Relationship of Adolescent Reproductive Health Levels with Premarital Sexual Attitudes}

When looking at the findings of the research between the amount of knowledge of teenage reproductive health and premarital sexual attitudes, they found substantial findings. The current focus on sexual attitudes and behaviors in adolescents is critical because it can have a direct impact on the youth population. The reasons for the occurrence of some of the most widespread premarital sexual attitudes are factors that can contribute to negative adolescent outcomes such as unwanted pregnancies, HIV/AIDS, and cervical cancer.

Teenagers at an age when sexual relations outside of marriage generate significant psychological issues for a person, such nervousness, guilt, despair, and others, have a psychologically immature age. People with higher levels of education tend to have better knowledge than those with lower levels of education, resulting in the increase in knowledge over time. In addition, people with higher levels of education are generally aware of how their age affects their knowledge increase, meaning that knowledge originates from the senses of sight, hearing, smell, taste, and touch. Of the 6 things that impact a person's attitude, there are six distinct elements.

These variables are a result of how others affect us, how our society impacts us, the effect of educational and religious institutions, as well as mass media, past experiences, and emotional impacts. Since personal experience is all we have to go on, it is something we encounter on a daily basis, such an emotion or a circumstance. This gives rise to real world instances, such as emotions and present circumstances, that may aid in our perceptions of 
various social circumstances. The reaction will be one of the foundational principles for the construction of attitudes. One must have some previous experience relating to the psychological item in order to have a reaction and an appreciation for it. To answer the question: Are teenagers' responses to sexual intercourse in the surrounding environment separated into two attitudes? The answer is: They are separated into those who support it (those who are negative) and those who do not support it (Positive). The way in which teenagers handle their sexuality before to marriage is very critical. Since excellent attitudes and better conduct are an anticipated outcome of young people with a positive mindset, they must avoid transgressing the norms if they want to continue maintaining a positive mindset. Adolescents who don't have healthy attitudes are more likely to engage in unruly conduct, such teenage pregnancy. This means that it is extremely essential to have the facts about reproductive health for adolescents while they are young so that they may be better prepared for adulthood.

\section{Conclusion}

An important factor in the future of the country is the group of adolescents which will make up the country's next generation. They are also important since they are responsible for investing in the country's future. As a result, the presence of youth groups cannot be denied. This is produced by several things, including the way in which the people conduct themselves, their way of life, and their unfamiliarity with the most current issues. This lack of awareness has, in fact, shown to be quite harmful to young groups and their families. The attitudes of teenagers when it comes to having sex before marriage are quite crucial. A positive attitude, with the intention that it would influence the teenager's conduct, is being formed to see whether their conduct is on track and whether they are adhering to the rules.

\section{References}

Adongo, P. B., Tapsoba, P., Phillips, J. F., Tabong, P. T. N., Stone, A., Kuffour, E., ... \& Akweongo, P. (2013). The role of community-based health planning and services strategy in involving males in the provision of family planning services: a qualitative study in Southern Ghana. Reproductive health, 10(1), 1-15.

Golub, M. S. (2000). Adolescent health and the environment. Environmental Health Perspectives, 108(4), 355-362.

Locke, D. C., \& Bailey, D. F. (2013). Increasing multicultural understanding. Sage Publications.

Marques, M., \& Ressa, N. (2013). The Sexuality Education Initiative: a programme involving teenagers, schools, parents and sexual health services in Los Angeles, CA, USA. Reproductive health matters, 21(41), 124-135.

Medic, G., Wille, M., \& Hemels, M. E. (2017). Short-and long-term health consequences of sleep disruption. Nature and science of sleep, 9, 151.

Tamanaha, B. Z. (2008). Understanding legal pluralism: past to present, local to global. Sydney L. Rev., 30, 375.

Townsend, J. W., ten Hoope-Bender, P., Sheffield, J., \& FIGO Contraception and Family Planning Committee. (2020). In the response to COVID-19, we can't forget health system commitments to contraception and family planning. International Journal of Gynecology \& Obstetrics, 150(3), 273-274. 
Warren, M. P., \& Perlroth, N. E. (2001). Hormones and sport-the effects of intense exercise on the female reproductive system. Journal of endocrinology, 170(1), 3-12.

Zhu, S., Zhang, T., Wang, Y., Zhou, X., Wang, S., \& Wang, Z. (2021). Meta-analysis and experimental validation identified atrazine as a toxicant in the male reproductive system. Environmental Science and Pollution Research, 1-16. 